\title{
Sociodemographic characteristics influencing birth outcome in Sweden, 1908-1930. Birth variables in The Population Study of Women in Gothenburg
}

\author{
Susan W Andersson, Aimon Niklasson, Leif Lapidus, Leif Hallberg, Calle Bengtsson, \\ Lena Hulthén
}

\begin{abstract}
Study objective-To identify variables available in early Swedish delivery records and their relation to birth outcomes for home and hospital deliveries in Gothenburg at the early part of this century.

Design-A retrospective recovery of original delivery records and social variables in a cross sectional population. Setting-Gothenburg, Sweden.

Participants-851 fullterm singleton female births with known gestational age born into five birth cohorts on selected dates (1908, 1914, 1918, 1922 and 1930).

Main results-Delivery site, maternal parity, gestational age, and social group were significant factors influencing birth outcome as birth weight and length. The mean birth weight and length of hospital born infants was consistently lower than for home deliveries across all cohorts. Site of delivery changed significantly during the period of births under study, 19081930.

Conclusions-In this study, which was based on original delivery records from the early part of this century, it was found that delivery site was an important factor influencing birth outcome across five birth cohorts. Utilisation of delivery services changed during the period of study. Thus, to avoid selection bias, the application of delivery records should reflect the birthing practice of the time period in question.
\end{abstract}

(F Epidemiol Community Health 2000;54:269-278)

Growth Research

Centre, Institute for

the Health of Women and Children,

Göteborg University

A Niklasson

Department of Medicine, Sahlgrenska

University Hospital,

Göteborg

L Lapidus

Department of

Primary Health Care,

Göteborg University,

C Bengtsson

Correspondence to:

$\mathrm{S}$ W Andersson

Accepted for publication 5 June 1999 this area have been unable to account for gestational age, have limited follow up possibilities and ignore social factors. ${ }^{18}{ }^{19}$ Furthermore, the quality of the underlying birth data needs to be assessed. There is a need for studies that answer these criticisms and to investigate further the explanatory mechanisms in support of or refuting the hypothesis.

Basic to studies of this hypothesis is the need for accurate data at the time of birth. Investigation into the relation between indicators at birth and morbidity in later life requires subjects to be middle aged to elderly at the time of study, thus requiring birth data dating back to the earlier part of the past century. Access to original maternity records for birth weight determination as well as various other variables at birth must be considered the gold standard. In Sweden, hospital and home birth delivery records from the 1800s onward have been well preserved in city and regional archives.

The overall interest in birth data is of a medical nature, however such data must also be seen in its historical perspective for proper interpretation of results and to be able to draw appropriate conclusions. Medical requirements, geographical proximity as well as social and economic aspects may influence the choice of delivery site, home or hospital, and these factors may change over time. If only hospital births are included in a study, do they reflect the norm for that period or was home delivery the current practice? Is there a difference in birth outcome for home as compared with hospital births that could then result in a biased sample if not all delivery sites are included in an investigation? What variables are available from delivery records and do they vary over time, which in turn would influence the data analysis? These questions are relevant when determining the suitability and applicability of any birth data.

The primary objective of this study was to examine birth outcome considering the anthropometric indicators birth weight and length, from original delivery records, in relation to sociodemographic factors at birth for home and hospital deliveries in the early part of the past century. As this database has far reaching potential for investigating the fetal origins hypothesis, factors and considerations in the application of early Swedish birth data are also discussed. 


\section{Methods}

A prospective population study of women was initiated in 1968-69 in Gothenburg, Sweden. ${ }^{20}$ Women born 1908, 1914, 1918, 1922 and 1930 on selected dates and residing in Gothenburg at the onset of the study were invited to participate in the investigation. A total of 1462 women participated at the onset, with follow up examinations in 1974-75, 1980-81 and 1992-93..$^{21-23}$ The systematic sampling method, based on date of birth, and a high participation rate $(90.1 \%$ of those invited), ensured that the women studied were a representative cross section of women from the community of the ages studied. To have a complete picture of the original birth cohorts of women, not only those who survived to the 1968 population study onset, all female live births in Gothenburg born on the study dates were identified from birth registers in the 22 parishes that comprised the city of Gothenburg in 1968. The present analysis is limited to female live births in Gothenburg.

DELIVERY RECORDS

Original delivery records with maternity data for the births of the study participants were traced in city and regional archives with additional sources including various county archives, health centres and even museums. Records are not computerised for that time period and thus each individual record was searched for based on the date of the subject's birth and the mother's name. Church records were used to confirm the mother's age, place of residence and parity (number of previous births), which were routinely recorded in the delivery records.

DELIVERY VARIABLES FROM MATERNITY RECORDS (1782-1930)

The information recorded in maternity records developed from very basic personal information in 1782 to relatively simple description in 1839 and to more precise measurements by the early 1900s. Standardised maternity data collection forms were used for home deliveries throughout the country and were periodically redesigned. Hospital delivery records throughout Sweden were more varied in design, although the basic contents were similar.

Home deliveries-Midwife records of 1908, in the format as found from 1881-1912, were basic in the information recorded. Mother's name, age, place of residence, number of previous births, and marital status were recorded. The course of delivery was noted from time of first labour pains, breaking of the amniotic sac (water), time of delivery of the infant and information on the birth of the placenta. For the infant (fetus), the birthing presentation, sex, maturity (full term or premature) and condition (alive or dead) were recorded. The mothers were checked again after one month and were noted as "healthy", "sick and bedridden" or "dead". It is important to note here that birth weight and birth length were not recorded until 1912 and 1917, respectively, for home deliveries.
Home deliveries in 1914, format in use from 1912 to 1917 , built upon the records described for 1908, however with several important additions. Date of last menstrual period was recorded, so that gestational age determinations were possible, and the birth weight of the infant was recorded. Parity was specified as number of live births, stillbirths and miscarriages. Also reported was the presence or absence of protein in the urine of the mother.

In addition to the variables mentioned above, birth length is found from 1917 onward and starting in 1926, even head circumference (table 1).

Hospital delivery records were more detailed than those for home births during the population study period 1908-1930. The record formats for the 1908 and 1914 cohorts were identical and were in use starting 1893. As with home birth records, mother's name, age (and date of birth), place of residence, number of previous live births, stillbirths and miscarriages as well as marital status were recorded. In addition, paternal information (if married) was included-as name and occupation of the father. Presence or absence of protein in the urine was recorded as was illness before and during the pregnancy. The delivery process was closely monitored and recorded with comments on external and internal examination of the mother. Birth weight, birth length, head circumference and weight of the infant at discharge were recorded. In addition to the data described above, placenta weight was recorded from April 1918 onward (table 1).

The only change in the 1930 hospital records was the addition of maturity determination, which was included from 1927 onward. This included the infant's skin colour, condition of the skin, fullness of the limbs, presence of "woolly hair" on the body and length of fingernails. All hospital records allowed room for comments by both the midwife and attending physician.

\section{PARENTAL CHARACTERISTICS AND} SOCIODEMOGRAPHIC VARIABLES

Information on sociodemographic characteristics was collected by thorough review of church birth registers in each parish and from the delivery records. Maternal marital status (unmarried, engaged, married, divorced or widowed) was determined from parish records. Married and engaged are considered together

Table 1 Birth variables : year of inclusion in delivery records, Gothenburg, Sweden

\begin{tabular}{lll}
\hline Variable & $\begin{array}{l}\text { Home } \\
\text { births }^{*}\end{array}$ & $\begin{array}{l}\text { Hospital } \\
\text { deliveryt }\end{array}$ \\
\hline Maternal marital status & 1881 & 1827 \\
Maternal age & 1881 & 1839 \\
Maternal parity & 1881 & 1839 \\
Birth weight & 1912 & 1878 \\
Birth length & 1917 & 1878 \\
Head circumference & 1926 & 1880 \\
DLMPł & 1912 & 1893 \\
Maternal proteinuria & 1912 & 1893 \\
Placenta weight & - & 1918 \\
Maturity determination & 1912 & 1927
\end{tabular}

${ }^{\star}$ Home births $=$ midwife records for home deliveries. $†$ Hospital delivery $=$ midwife records in hospital. $\neq$ DLMP $=$ date of last menstrual period. 
here as "married" because engaged was an accepted form of cohabitation (in the eyes of the church) for the birth period studied. "Unmarried" includes unmarried, divorced and widowed mothers.

Maternal age was recorded in all delivery records and/or was available from parish records. Maternal parity, defined here as number of births (live and stillborn) before the birth of the subject under study, was collected from the delivery records supplemented with church records.

Parental social group, from parish records, was based on the father's occupation at the time of the birth or if the parents were not married, then the mother's occupation. Parental occupation was classified into five socioeconomic groups according to Carlsson. ${ }^{24}$ Group I according to this classification were large scale employers, professionals and officials of high rank. Group II includes small scale employers, landowners and officials of intermediate rank. Group III represents officials of lower rank and foremen. Both Group II and III are considered "middle class" occupations. Group IV included skilled workers and Group V was unskilled manual workers.

Delivery site was defined as home, hospital or private maternity home. Home deliveries were attended by a trained midwife who was required to record specific information for each birth and to further report to the city or provincial medical officer in charge. A medical doctor could be called for assistance in difficult cases, however even instrument assisted deliveries could be carried out by midwives trained for this task. ${ }^{25}$ There was only one maternity hospital in Gothenburg during the period of investigation (1908-1930), called "Barnbördshuset". Births were attended by trained midwives and midwifery students. A medical doctor was called in for complications, instrument assisted births and for placenta extraction. From 1911, a private maternity home was also available, which was run by two midwives
(Göteborgs Privata Förlossningshem) that later included more advanced maternity and gynaecological care.

For the purpose of this report, birth weight and birth length are examined as they are the main outcome variables to be found in both home and hospital delivery records.

\section{STATISTICAL METHODS}

Standard methods were used to calculate mean values, standard deviations, $\chi^{2}$, Spearman correlation, two sample $t$ tests and construction of $95 \%$ confidence intervals. Probit analysis (Normal plot) as described by Altman was used to examine the distribution of birth weights by cohort. ${ }^{26}$ For comparison, the probit plot also includes raw data from the Swedish Medical Birth Registry, comprising all fullterm live singleton female infants born in Sweden 1991-1995 to determine birth weight distribution in a modern Swedish population. Trends in birth weight and sociodemographic factors were assessed by simple linear regression. Analysis of covariance was performed with birth weight and birth length as dependent variables. The initial models included those covariates we believed would contribute to the model as independent variables (birth cohort membership, delivery site, maternal age, maternal marital status, maternal parity, gestation time and parental social group) and in interaction: birth cohort and maternal age, parental social group and maternal marital status and birth cohort and delivery site. As the effect of cohort differed between delivery sites (no trend for home delivery while a positive trend for hospital), as a more intuitive model we reparameterised site and cohort into separate cohort effects for each delivery site. Gestational age cannot equal zero, thus this variable was transformed to gestation minus a centred value of 40 weeks (gestation-40 weeks). The intercept therefore reflects the predicted birth weight/length where gestation equals 40 weeks while the remaining covariates originate at

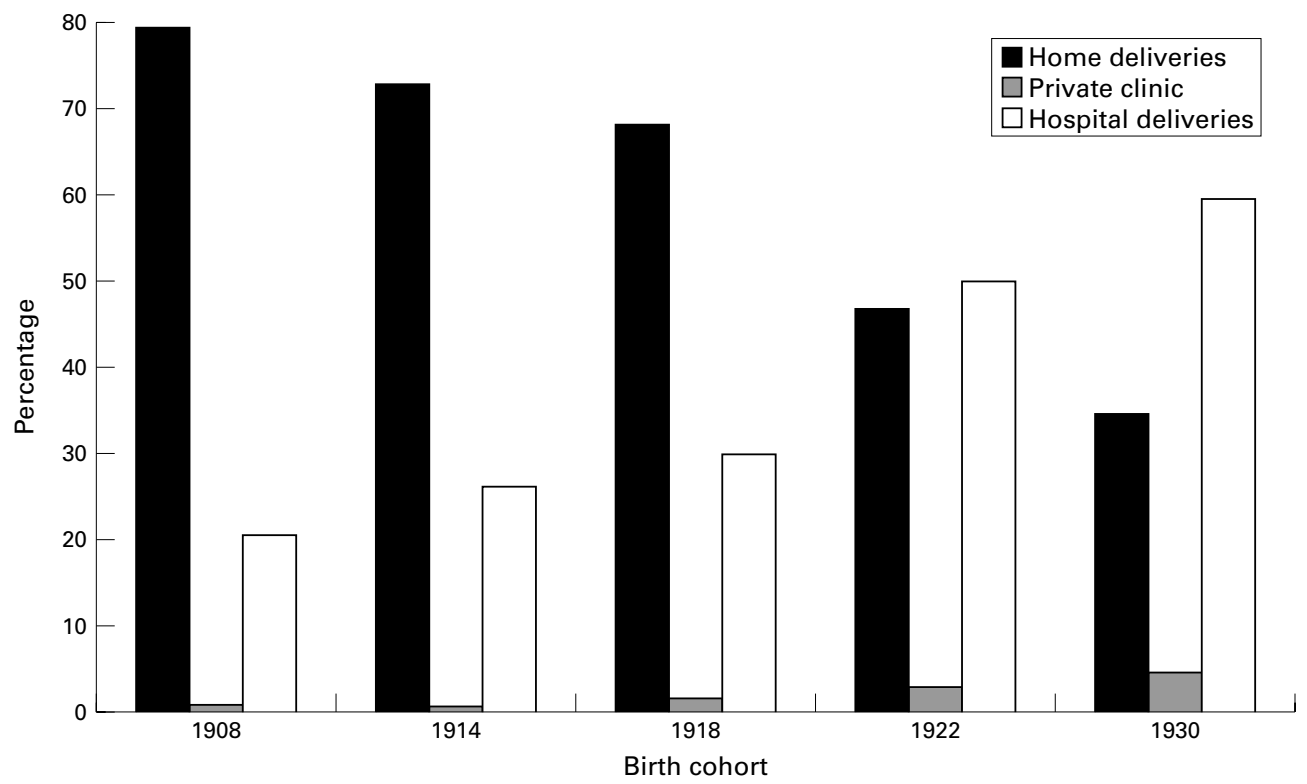

Figure 1 Trend in delivery site in Gothenburg, Sweden by birth cohort 1908-1930. 
zero. The SAS software release 6.12 statistical package was used for all analyses and probit plot.

\section{Results}

BIRTH DATA

There were 1287 live female births in Gothenburg on the study dates for the five cohorts under investigation. Original delivery records

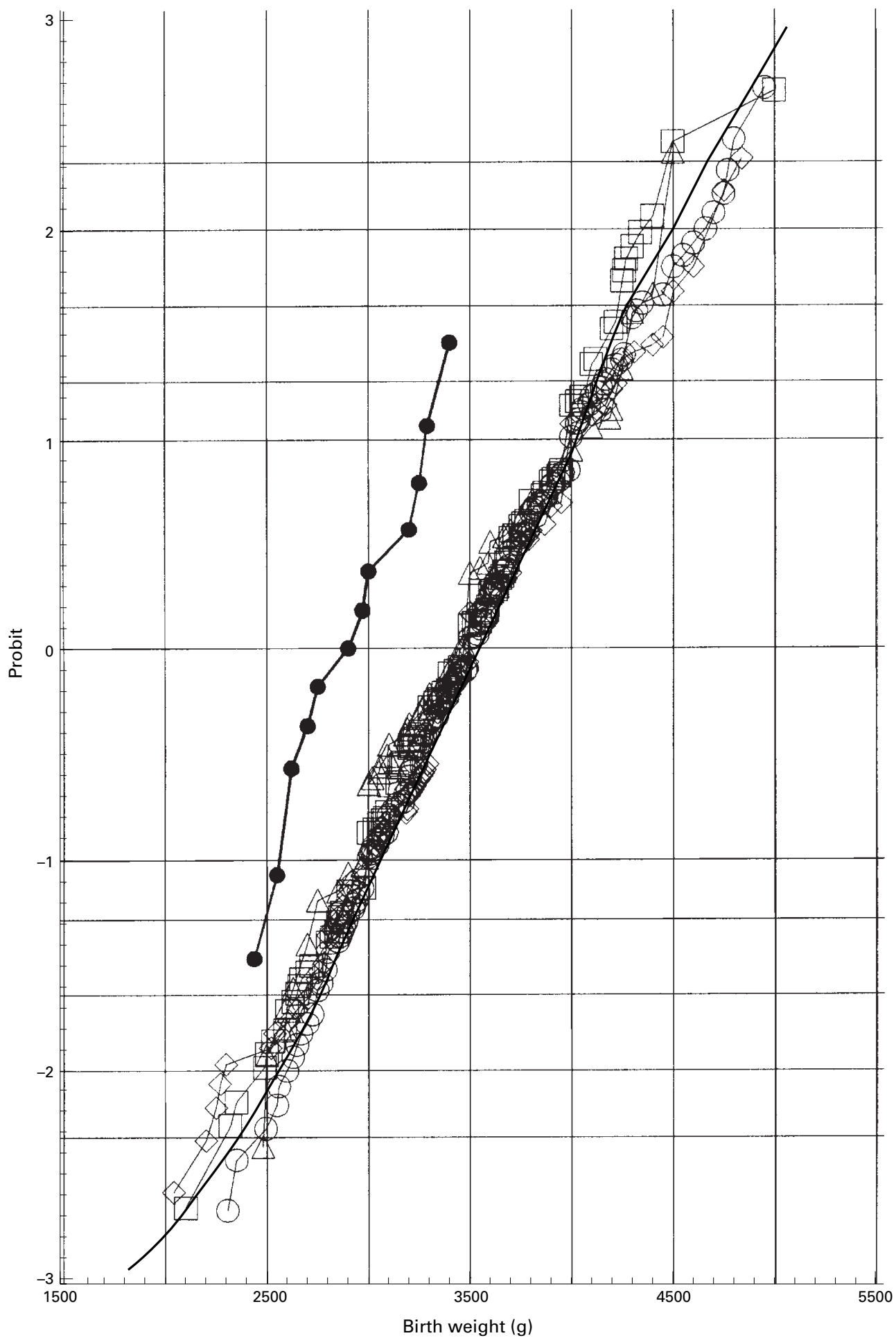

for $84 \% \quad(n=1084)$ of the women born in Gothenburg were retrieved of which 1021 included data on birth weight. For the analyses presented here, only singleton births with known gestational age $>37$ weeks but less than 45 weeks, and for whom birth weight was recorded are considered. Excluded were 17 twins (mean birth weight $2692 \mathrm{~g}$, SD $366 \mathrm{~g}$ ),

Figure 2 Distribution of birth weights by probit analysis for five fullterm singleton female birth cohorts born 1908-1930 in Gothenburg, Sweden, and comparison with all fullterm live singleton females born in Sweden 1991-1995. 1908=solid dot (includes hospital deliveries only) 1914=triangle 1918=diamond 1922=square 1930=circle and 1991-1995=heavy line. From the bottom of the figure and upwards, the vertical reference lines represent 1, about 2.3 (probit $=-2$ ), 5, 10, about 15.9 (probit=-1), 50 (probit=0=median), about 84.1 (probit=1), 90, 95, about 97.7 (probit=2) and 99\% of the distributions. 
Table 2 Correlation matrix of sociodemographic variables and birth outcome as weight and length at birth: fullterm singleton births, cohorts combined $(n=837)$, Spearman correlation coefficients ( $p$ value). (1908 cohort excluded for birth weight, 1908 and 1914 excluded for birth length)

\begin{tabular}{|c|c|c|c|c|c|c|c|c|}
\hline & Birth weight & Birth length & Delivery site & $\begin{array}{l}\text { Maternal } \\
\text { marital status }\end{array}$ & Maternal age & $\begin{array}{l}\text { Maternal } \\
\text { parity }\end{array}$ & $\begin{array}{l}\text { Gestational } \\
\text { age }\end{array}$ & Birth cohort \\
\hline Birth length $(n=686)$ & $0.64(0.001)$ & & & & & & & \\
\hline Delivery site (home $=1$, hospital $=2$ ) & $-0.29(0.001)$ & $-0.21(0.001)$ & & & & & & \\
\hline Maternal marital status & & & & & & & & \\
\hline (unmarried $=0$, married $=1$ ) & $0.13(0.001)$ & $0.09(0.05)$ & $-0.11(0.01)$ & & & & & \\
\hline Maternal age & $0.15(0.001)$ & $0.13(0.01)$ & $-0.21(0.001)$ & $0.21(0.001)$ & & & & \\
\hline Maternal parity & $0.28(0.001)$ & $0.18(0.001)$ & $-0.26(0.001)$ & $0.19(0.001)$ & $0.58 \quad(0.001)$ & & & \\
\hline Gestational age & $0.21(0.001)$ & $0.24(0.001)$ & $-0.02(0.52)$ & $0.02(0.49)$ & $0.0004(0.99)$ & $0.01(0.71)$ & & \\
\hline Birth cohort $(1-4)^{\star}$ & $0.02(0.55)$ & $0.09(0.05)$ & $-0.23(0.001)$ & $0.12(0.001)$ & $-0.02 \quad(0.55)$ & $-0.10(0.01)$ & $0.03(0.38)$ & \\
\hline Parenteral social group $(\mathrm{I}-\mathrm{V}) \dagger$ & $-0.03(0.35)$ & $-0.07(0.07)$ & $0.10(0.01)$ & $-0.17(0.001)$ & -0.09 & $0.05(0.28)$ & $-0.01(0.88)$ & $0.03(0.38)$ \\
\hline
\end{tabular}

${ }^{\star} 1=1914,2=1918,3=1922,4=1930$, tif married then father's occupation, otherwise mother's.

Table 3 Univariate analysis of birth weight and sociodemographic characteristics - full term singleton female births, 1908 cohort excluded

\begin{tabular}{|c|c|c|c|c|}
\hline \multirow[b]{2}{*}{ Characteristic } & \multirow[b]{2}{*}{ Number } & \multicolumn{2}{|c|}{ Birth weight (g) } & \multirow[b]{2}{*}{$p$ value } \\
\hline & & mean $(S D)$ & $95 \% C I$ & \\
\hline \multicolumn{5}{|l|}{ Delivery site } \\
\hline Home & 354 & $3683(523)$ & 3628,3738 & \multirow[t]{2}{*}{$0.001^{\star}$} \\
\hline Hospital & 452 & $3371(470)$ & 3327,3414 & \\
\hline \multicolumn{5}{|c|}{ Maternal marital status } \\
\hline Unmarried & 113 & 3339 (489) & 3247,3430 & \multirow[t]{2}{*}{$0.001^{\star}$} \\
\hline Married & 724 & 3535 (519) & 3497,3573 & \\
\hline \multicolumn{5}{|l|}{ Maternal age } \\
\hline$<20$ & 40 & $3411(463)$ & 3263,3559 & \multirow[t]{5}{*}{$0.001 \dagger$} \\
\hline $20-24$ & 195 & 3406 (534) & 3330,3481 & \\
\hline $25-29$ & 238 & $3527(527)$ & 3460,3594 & \\
\hline $30-34$ & 203 & $3508(481)$ & 3442,3575 & \\
\hline$>35$ & 161 & $3629(525)$ & 3548,3711 & \\
\hline \multicolumn{5}{|c|}{ Maternal parity } \\
\hline 0 & 325 & $3331(499)$ & 3277,3386 & \multirow[t]{4}{*}{$0.001 \dagger$} \\
\hline 1 & 196 & $3575(472)$ & 3508,3641 & \\
\hline $2-3$ & 193 & $3616(538)$ & 3540,3692 & \\
\hline $4+$ & 123 & $3701(475)$ & 3717,3786 & \\
\hline \multicolumn{5}{|c|}{ Parental social group } \\
\hline 1 & 35 & $3596(503)$ & 3423,3769 & \multirow[t]{6}{*}{$0.35 \ddagger \S$} \\
\hline 2 & 77 & $3462(411)$ & 3368,3555 & \\
\hline 3 & 149 & $3549(505)$ & 3468,3632 & \\
\hline 4 & 265 & $3501(545)$ & 3435,3567 & \\
\hline 5 & 287 & $3493(538)$ & 3431,3555 & \\
\hline missing & 24 & $3535(409)$ & 3254,3816 & \\
\hline
\end{tabular}

$95 \% \mathrm{CI}=95 \%$ confidence intervals, ${ }^{\star}$ two sample $t$ test, †test for trend (as continuous variable), $\ddagger$ Spearman trend test, §missing values not included in trend test.

Table 4 Univariate analysis of birth length and sociodemographic characteristics - full term singleton female births, 1908 and 1914 cohorts excluded

\begin{tabular}{|c|c|c|c|c|}
\hline \multirow[b]{2}{*}{ Characteristic } & \multirow[b]{2}{*}{ Number } & \multicolumn{2}{|c|}{ Birth length $(\mathrm{cm})$} & \multirow[b]{2}{*}{$p$ value } \\
\hline & & mean $(S D)$ & $95 \% C I$ & \\
\hline \multicolumn{5}{|l|}{ Delivery site } \\
\hline Home & 219 & $50.9(2.9)$ & $50.5,51.3$ & \multirow[t]{2}{*}{$0.001^{\star}$} \\
\hline Hospital & 411 & $50.0(1.9)$ & $49.9,50.2$ & \\
\hline \multicolumn{5}{|c|}{ Maternal marital status } \\
\hline Unmarried & 82 & $49.9(2.5)$ & $49.3,50.4$ & \multirow[t]{2}{*}{$0.10^{\star}$} \\
\hline Married & 563 & $50.4(2.3)$ & $50.2,50.6$ & \\
\hline \multicolumn{5}{|l|}{ Maternal age } \\
\hline$<20$ & 27 & $50.1(1.3)$ & $49.6,50.6$ & \multirow[t]{5}{*}{$0.01 \dagger$} \\
\hline $20-24$ & 164 & $50.0(2.1)$ & $49.7,50.3$ & \\
\hline $25-29$ & 183 & $50.2(2.1)$ & $49.9,50.5$ & \\
\hline $30-34$ & 150 & $50.4(2.4)$ & $50.0,50.8$ & \\
\hline$>35$ & 121 & $50.8(2.7)$ & $50.3,51.3$ & \\
\hline \multicolumn{5}{|c|}{ Maternal parity } \\
\hline 0 & 255 & $49.8(2.2)$ & $49.5,50.1$ & \multirow[t]{4}{*}{$0.001 \dagger$} \\
\hline 1 & 151 & $50.6(1.9)$ & $50.3,50.9$ & \\
\hline $2-3$ & 148 & $50.6(2.1)$ & $50.3,51.0$ & \\
\hline $4+$ & 91 & $50.8(3.2)$ & $50.1,51.5$ & \\
\hline \multicolumn{5}{|c|}{ Parental social group } \\
\hline 1 & 19 & $50.6(1.8)$ & $49.7,51.5$ & \multirow[t]{6}{*}{$0.05 \ddagger 8$} \\
\hline 2 & 50 & $50.5(2.2)$ & $49.9,51.1$ & \\
\hline 3 & 110 & $50.9(2.1)$ & $50.5,51.3$ & \\
\hline 4 & 219 & $50.1(2.3)$ & $49.8,50.5$ & \\
\hline 5 & 228 & $50.2(2.2)$ & $49.9,50.5$ & \\
\hline missing & 19 & $49.5(4.0)$ & $47.6,51.4$ & \\
\hline
\end{tabular}

$95 \% \mathrm{CI}=95 \%$ confidence intervals, ${ }^{\star}$ two sample $t$ test, ttest for trend (as continuous variable), $\ddagger$ Spearman trend test, \missing values not included in trend test.

47 births with unknown gestational age (3508 g, SD $589 \mathrm{~g}), 92$ pre-term (<37 weeks) $(2872 \mathrm{~g}, \mathrm{SD} 798 \mathrm{~g})$ and 14 post-term (>45 weeks) (3724 g, SD $429 \mathrm{~g}$ ) births as calculated from date of last menstrual period. Twin births were removed from the analysis as birth weight is known to be lower than average than for singleton births. ${ }^{27} \mathrm{~A}$ total of 851 female births were finally eligible for inclusion. Maternal characteristics (from parish registers) did not differ between mothers for whom original delivery records were retrieved (and therefore included in the following analyses) and those for whom records were not traced. No significant differences were found in maternal age ( $\mathrm{p}=0.70$, two sample $t$ test), maternal parity ( $\mathrm{p}=0.21$, two sample $t$ test) nor in maternal marital status $\left(\chi^{2}=3.4, p=0.07\right)$.

\section{TREND IN DELIVERY SITE}

Figure 1 illustrates the trends in the utilisation of delivery services during the period of the births of the five cohorts. In 1908, 79\% of all births took place in the home while by 1930 the majority of births $(60 \%)$ took place in hospital. A strong linear trend $\left(\chi^{2}=104.8, \mathrm{p}<0.0001\right)$ was found for the increase in hospital births over time. For the same period, a significant increase in births at the private facility occurred $\left(\chi^{2}=9, p=0.003\right)$ even if the number of cases $(n=32)$ was small.

DISTRIBUTION OF BIRTH WEIGHTS

The distribution of birth weights of the five birth cohorts by probit analysis is presented in figure 2 . The plot shows that the birth weights of the latest four cohorts have a reasonably straight line (normal) distribution with a median birth weight of approximately $3500 \mathrm{~g}$. The birth weight distributions of these early cohorts are similar to that of a modern population using the birth weight distribution (heavy solid line) of all fullterm female singleton live births in Sweden born 1991-1995 for comparison. The oldest cohort, those born 1908, shows a divergence from the other four cohorts. Birth weight was not recorded for home births in 1908 and thus only hospital births for 1908 are represented in the probit plot.

SOCIAL FACTORS

The proportion of unmarried mothers decreased from $21 \%$ in 1908 to $11 \%$ in 1930 . With respect to delivery site, unmarried mothers in the hospital setting accounted for $40 \%$ of the births in 1908 gradually decreasing to $9 \%$ in the 1930 cohort. On the other hand for home births, the proportion of unmarried mothers remained relatively stable throughout the five cohort periods $(17,18,12,9,16 \%$, respectively, 1908 to 1930 ). 


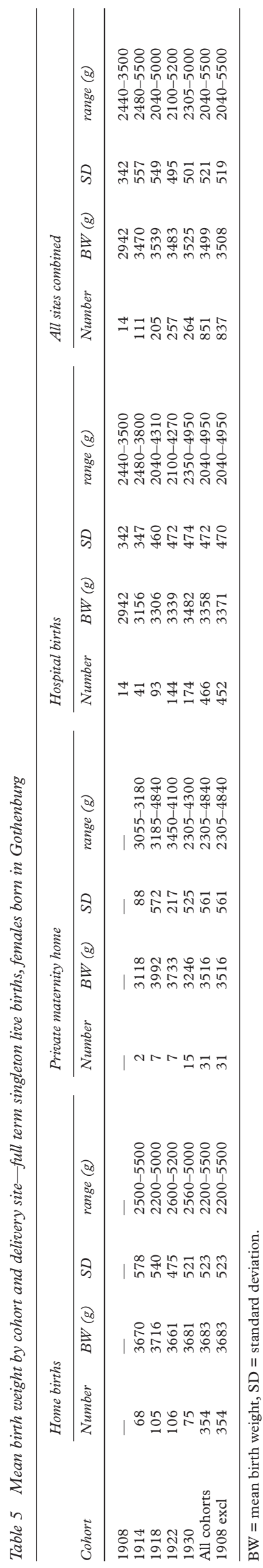

KEY POINTS

- Delivery site (home or hospital), maternal parity and gestational age influence birth outcome as birth weight and length.

- Weight and length of hospital born infants at the early part of the 20th century were consistently lower than for infants delivered at home.

- Inclusion of delivery records should reflect delivery services for the time period under study to avoid selection bias.

Only $5 \%$ of the mothers were under 20 years of age at the time of the birth of the infant under study. Forty three per cent of the mothers were 30 years or older.

The proportion of primiparous births was consistently higher in the hospital setting than for home births across all cohorts. For hospital births: 30, 56, 47, 43, 52\%, respectively 1908 to 1930 . For home births: $21,25,22,23,37 \%$, respectively 1908 to 1930 . Of the multiparous mothers, with four or more previous births, $74 \%$ gave birth at home. Of the total primiparous mothers, $20 \%$ were unmarried. Of the unmarried mothers, $61 \%$ were primiparous in contrast with $37 \%$ of those who were married.

Birth weight and length were significantly positively correlated with maternal marital status (higher birth weight and length in infants born to married mothers), maternal age, maternal parity and gestational age (table 2). Birth weight and length were negatively correlated with delivery site (lower birth weights and lengths found in hospital births), analysed with all cohorts combined. Delivery site, (home compared with hospital), was significantly negatively associated with maternal marital status (unmarried mothers gave birth more frequently in the hospital setting), maternal age (younger mothers delivered in hospital), maternal parity and cohort membership (those women born in the earlier cohorts were more frequently delivered at home). Lower social groups tended to deliver in hospital.

SOCIAL FACTORS IN RELATION TO BIRTH WEIGHT AND LENGTH

Univariate analysis of birth weight and parental sociodemographic characteristics at the time of the birth is shown in table 3 and for birth length in table 4 . The 1908 cohort is excluded $(n=14)$ from the birth weight analyses because of the lack of birth weight data for home deliveries for that cohort. For the same reason, the 1908 and 1914 cohorts are excluded from birth length analyses $(n=125)$.

Infants born in hospital weighed significantly less than home deliveries $(\mathrm{p}<0.001$, two sample $t$ test) (table 3). Birth weights of infants born to unmarried mothers were significantly lower than for infants born to married mothers for cohorts combined $(\mathrm{p}<0.001$, two sample $t$ test). This held true at the individual cohort level for the 1914 and 1918 cohorts. However, there was no significant difference in birth weight for home and hospital births for the 
Table 6 Mean length at birth by cohort and delivery site-full term singleton live births, females born in Gothenburg

\begin{tabular}{|c|c|c|c|c|c|c|c|c|c|c|c|c|c|c|c|c|}
\hline \multirow[b]{2}{*}{ Cohort } & \multicolumn{4}{|c|}{ Home births } & \multicolumn{4}{|c|}{ Private maternity home } & \multicolumn{4}{|c|}{ Hospital births } & \multicolumn{4}{|c|}{ All sites combined } \\
\hline & Number & $\begin{array}{l}B L \\
(\mathrm{~cm})\end{array}$ & $S D$ & $\begin{array}{l}\text { range } \\
(\mathrm{cm})\end{array}$ & Number & $\begin{array}{l}B L \\
(\mathrm{~cm})\end{array}$ & $S D$ & $\begin{array}{l}\text { range } \\
(\mathrm{cm})\end{array}$ & Number & $\begin{array}{l}B L \\
(\mathrm{~cm})\end{array}$ & $S D$ & $\begin{array}{l}\text { range } \\
(\mathrm{cm})\end{array}$ & Number & $\begin{array}{l}B L \\
(\mathrm{~cm})\end{array}$ & $S D$ & $\begin{array}{l}\text { range } \\
(\mathrm{cm})\end{array}$ \\
\hline 1908 & - & - & - & - & - & - & - & - & 14 & 48.5 & 1.4 & $46-51$ & 14 & 48.5 & 1.4 & $46-51$ \\
\hline 1914 & - & - & - & - & - & - & - & - & 41 & 49.1 & 1.8 & $45-54$ & 41 & 49.1 & 1.8 & $45-54$ \\
\hline 1918 & 72 & 50.6 & 3.2 & $35-58$ & - & - & - & - & 93 & 49.8 & 2.5 & $36-54$ & 165 & 50.1 & 2.8 & $35-58$ \\
\hline 1922 & 72 & 50.8 & 2.9 & $40-58$ & - & - & - & - & 144 & 50.1 & 1.9 & $46-58$ & 216 & 50.4 & 2.3 & $40-58$ \\
\hline 1930 & 75 & 51.3 & 2.5 & $40-58$ & 15 & 49.4 & 1.6 & $47-53$ & 174 & 50.1 & 1.5 & $47-55$ & 264 & 50.4 & 1.9 & $40-58$ \\
\hline All cohorts & 219 & 50.9 & 2.9 & $35-58$ & 15 & 49.4 & 1.6 & $47-53$ & 466 & 49.9 & 1.9 & $36-58$ & 700 & 50.2 & 2.3 & $35-58$ \\
\hline 1908/1914 excluded & 219 & 50.9 & 2.9 & $35-58$ & 15 & 49.4 & 1.6 & $47-53$ & 411 & 50.0 & 1.9 & $36-58$ & 645 & 50.3 & 2.3 & $35-58$ \\
\hline
\end{tabular}

$\mathrm{BL}=$ mean birth length, $\mathrm{SD}=$ standard deviation.

Table 7 Regression model for birth weight ( $F=40.1$, $\left.p<0.0001, r^{2}=0.17\right)$

\begin{tabular}{lcc}
\hline & $\beta$ coefficient & $p$ value \\
\hline Intercept & 3149.2 & 0.0001 \\
Parity & 46.2 & 0.0001 \\
Gestational age & 50.3 & 0.0001 \\
Birth cohort ${ }^{\star}$ and site=home & -14.9 & 0.38 \\
Birth cohort ${ }^{\star}$ and site=hospital & 106.4 & 0.0001 \\
\hline${ }^{\star}$ Where birth cohort $0=1914,1=1918,2=1922,3=1930$.
\end{tabular}

Table 8 Regression model for birth length $(F=14.2$, $p<0.0001, r^{2}=0.10$ )

\begin{tabular}{|c|c|c|}
\hline & $\beta$ coefficient & $p$ value \\
\hline Intercept & 50.0 & 0.0001 \\
\hline Parity & 0.2 & 0.0001 \\
\hline Gestational age & 0.3 & 0.0001 \\
\hline Parental social group & -0.2 & 0.01 \\
\hline Birth cohort $^{\star}$ and site $=$ home & 0.002 & 0.98 \\
\hline Birth cohort ${ }^{\star}$ and site $=$ hospital & 0.3 & 0.006 \\
\hline
\end{tabular}

*Where birth cohort $0=1918,1=1922,2=1930$.

1922 and 1930 with respect to maternal marital status (two sample $t$ test). The mean birth weight of infants born to unmarried mothers was $196 \mathrm{~g}$ lighter than for infants born to married mothers (cohorts combined). Test for trend showed that birth weights increased significantly with maternal age $(p<0.001)$ and with increasing parity $(\mathrm{p}<0.001)$ but not with parental social group (table 3 ).

Infants born in hospital were significantly shorter than home delivered $(\mathrm{p}<0.001$, two sample $t$ test) (table 4). Birth length showed a significant positive increase with increasing maternal age and maternal parity, but no difference by maternal marital status. There was evidence of a trend between birth length and parental social group $(\mathrm{p}<0.05)$.

Mean birth weights for the three delivery sites-home, hospital and private facility-are presented in table 5 by cohort and total study population. The mean birth weight for home deliveries was significantly higher (3683 g SD $524 \mathrm{~g}$ ) than for hospital deliveries (3358 g SD $472 \mathrm{~g})$ ( $\mathrm{p}<0.001$, two sample $t$ test). Home births weighed consistently significantly more than hospital births across all cohorts $(\mathrm{p}<0.0001)$. Within delivery site, simple linear regression showed a significant positive trend in birth weights over time for hospital births $(p<0.0001)$. No trend was seen for home births.

The mean length at birth was significantly longer for home births $(50.9 \mathrm{~cm} \mathrm{SD} \mathrm{2.9)}$ than for hospital births (49.9 cm SD 1.9) ( $\mathrm{p}<0.001$, two sample $t$ test) for cohorts combined (1918, 1922 and 1930 included in analysis) (table 6). However, at the cohort level, only the 1930 cohort differed significantly by delivery site. No trend was found for birth length and delivery site (1918-1930 cohorts). However, when all cohorts were included, 1908-1930, a significant positive trend was found $(p<0.001)$ for hospital deliveries.

MODELLING BIRTH WEIGHT AND BIRTH LENGTH The initial linear model for birth weight, which included the covariates: birth cohort, delivery site, maternal age, marital status and parity, gestation time and social group, resulted in an $F=13.52, \mathrm{p}<0.0001$. However, parental social group, maternal age and maternal marital status did not contribute to the model (where $\mathrm{p}=0.92,0.80$ and 0.60 , respectively) nor did the interactions incorporating these variables and were removed from the model in further steps. Delivery site alone did not contribute to the model, however the interaction birth cohort and delivery site did. After reparameterisation, the estimated birth cohort effect for home deliveries was not significant. However, the cohort effect for hospital deliveries was highly significant. The final model for birth weight is shown in table 7 where $F=40.01, \mathrm{p}<0.0001$, $r^{2}=0.17$.

For birth length, only the 1918, 1922 and 1930 cohorts were included. The resulting initial model had an $F=7.33, \mathrm{p}<0.0001$. Maternal marital status and maternal age did not contribute to the model ( $p=0.71,0.21$, respectively) and were removed in further analysis. Cohort membership did not independently contribute to the model after the removal of maternal marital status and maternal age. After reparameterisation, there was a significant cohort effect on birth length for hospital births but not for home births. The final model is shown in table 8 where $F=14.2, \mathrm{p}<0.0001$ and $r^{2}=0.10$.

\section{Discussion}

The measures and information recorded in early Swedish delivery records (1782-1930) have evolved over time. Variables such as birth weight and birth length, major factors of interest in the investigation of the fetal origins hypothesis, are only found from 1912 and 1917 onwards, respectively, for all sites, limiting the usefulness of earliest data. Inclusion of date of last menstrual period makes it possible to account for gestation time. As a number of social factors can be derived directly from birth records, this data source is not only unique in providing a means to ascertain anthropometric 
indicators but even accounting for effect of various social indicators.

All births in Sweden (including stillborn) have been systematically recorded in each parish for over 300 years. It was the duty of all persons to inform the local parish that a person was leaving the parish and to report to the new parish to be recorded there. This function and the unique 10 digit personal identification number issued to all persons in Sweden makes it possible to follow up persons prospectively as well as retrospectively through the life span. This in turn makes it possible to trace the name of the subject's mother necessary for locating delivery records. This is especially important in tracing adult female subjects because of the change in surname with marriage.

One might question the quality of birth outcome measurements made earlier in the early 1900s. All midwives were required to have formal training from 1907 with nine months general midwifery complemented with three months training in instrument assisted delivery. ${ }^{28}$ In 1908 every county in Sweden was required to employ a trained midwife. ${ }^{28}$ By the year 1924, a two year midwife training programme was started. Obstetrical data for home and hospital births for men born in 1913 in Sweden were evaluated by Eriksson and coworkers where they found the records to be of good validity. ${ }^{29}$ In our study, the distribution of birth weights of fullterm female infants, as shown in figure 2 , follows that of a modern day population that also indicates good quality of the early birth weight data. Probit analysis of birth length (not shown) found a similar distribution as for birth weight, again indicating data quality.

Many previous studies on the relation between birth weight and later morbidity have been based on maternal recall or self reporting of birth weight. ${ }^{51315163031}$ Recalled and self reported birth weight data may be subject to errors of memory and are often limited by categorisation into pre-determined birth weight divisions. It is understandable that where there is no possibility to attain original delivery records that reported birth data may be the only solution. However, that error and even systematic bias may occur cannot be ruled out. A strong correlation between reported and original birth weights is not enough to accept the validity of reported measures. Agreement between measurements must also be assessed. $^{32}$

In this study we achieved a high rate (84\%) of recovery of original delivery records for women born in Gothenburg. Where records were not found, it can be assumed that these were home births. The hospital birth recording system, where each birth is recorded in a hospital birth record book, acts as a confirmation for the records bound in the archives. Full coverage can be assumed. For the home deliveries, no systematic recording, beyond the records in each midwifes recording diary, was available for confirmation. However, after thorough review of parish birth notifications, we were able to ascertain for $47 \%$ of the missing records that these were home deliveries as the notifications were frequently signed by the attending midwife and/or from a notation in the parish birth record book. Missing records were not likely to be selective as, for the most part, they reflected specific midwives where the material was not handed over to the archive authorities. Even "secret" births, where the mother's name "unknown" and the mother's date of birth and parish were routinely recorded in the delivery records, were traceable from birth through adulthood by means of parish records.

In this study we have been strict in defining fullterm gestation. We have excluded all births where no date of last menstrual period was reported as well as calculated gestation time of less than 37 weeks and greater than 45 weeks. Lack of menstruation between pregnancies is a partial explanation for missing data. The reported date of last menstruation is of course subject to errors of memory. However, at this period in time (1908-1930), the "rhythm method" was essentially the only form of pregnancy prevention available leading to the assumption that women were most probably conscious of their menstrual cycles.

The period of birth covered by the population study, 1908-1930, illustrates a period of transition in the utilisation of delivery services in Gothenburg. A shift in delivery site occursfrom a majority of home births for the 1908 cohort to a slight majority of hospital births for the 1930 cohort as was shown in figure 1 . At a national level, Höjeberg reported a shift in home births from $90 \%$ at the end of the 1800 s to $35 \%$ in $1940 .{ }^{28}$ This is important to consider as birth data collected from hospital records only, (which are more easily accessed than home delivery records), may not be representative of the current practice of the time period investigated leading to a systematic bias in the data.

Previous studies may have been biased by including only hospital deliveries. ${ }^{6} 7143334$ In a Swedish study, evidence of a positive, but not statistically significant, association between birth weight (from hospital deliveries only) and breast cancer in adulthood was found. ${ }^{14}$ One can speculate that significance may have been reached had the study included all delivery sites, with the knowledge that home births, on average, were heavier than hospital births for that time period. In the early 1900 s, women in Sweden who sought hospital-based delivery were often poor, unmarried, had no home where they could deliver, or were considered at high risk for complications. ${ }^{25}$ A review of hospital delivery records for the late 1800 s in Gothenburg found that $70 \%$ of the mothers were unmarried in 1880 (unpublished observation, SWA) while in our data for 1908 the proportion of unmarried hospital deliveries had reduced to $40 \%$.

The probit plot (fig 2) serves to illustrate the importance of a representative inclusion of delivery records to cover all forms of delivery service for the period of investigation. The shift towards lower birth weights for the hospital born births for the 1908 cohort, which accounted for less than $30 \%$ of the births for 
that cohort, illustrates the bias that may result from the utilisation of hospital records only. Probit plots for the other cohorts treating delivery sites separately (not shown here), showed a similar shift, with consistently lower birth weights and lengths for hospital births across all cohorts. Again, this illustrates the importance of including all delivery sites to avoid a selection bias. The inclusion of only hospital births for this time period would result in an over representation of births of high risk pregnancies, unmarried mothers and groups of lower socioeconomic status all factors known to negatively influence birth outcome.

Social indicators, as covariates or confounding factors, are important in the analysis and interpretation of birth data. However, such information has been found to be lacking in studies of the fetal origins of disease. ${ }^{19}$ Social factors may influence choice of maternity services and directly play a part in birth outcome. ${ }^{35}$

The finding that mean birth weights in this study were significantly different dependent on delivery site may be a consequence of social and medical factors influencing choice of delivery site. This was illustrated by the consistent lower birth weights found for hospital births for the earliest cohorts studied through to the latest (1914-1930). The overall test of the model is clearly significant (tables 7 and 8 ). However, a substantial portion of the variance is still unexplained as evidenced by the $r^{2}$, although better for birth weight than birth length in the models presented. The only social factor that contributed significantly to the birth weight model was delivery site, while for birth length, both social group and delivery site were significant. Maternal parity and gestational age contributed significantly to both models. Although the study design did not permit inclusion of other known factors influencing size at birth such as smoking and alcohol consumption during pregnancy, these factors were not common practice for women during the time period under study (1908-1930). Our finding of a strong association between delivery site and birth weight is supported in a study of men born 1913 in Gothenburg. ${ }^{29}$

The increase in birth weight and length in hospital born infants for the period 1908 to 1930 may be explained by the gradual shift from home to hospital births during this period. As the proportion of home births diminished and hospital delivery became the more accepted delivery site, births that previously would have taken place in the home moved to the hospital setting contributing to the birth weight and length increase. The proportion of unmarried mothers, however, remained higher for hospital births in the four earliest cohorts while in the 1930 cohort a downward shift was found. Primiparous births accounted for $48 \%$ of hospital births for all cohorts combined. On the other hand, only $25 \%$ of the home births were primiparous. As first borns are known to weigh less than their later siblings, ${ }^{36}$ this factor would also contribute to the lower birth weights for the hospital born population.
Social group was not found to have a significant effect on birth outcome in this study when classifying the occupational group based on the mother's occupation if unmarried, and the father's if the parents were betrothed or married. This is the common method of classifying social group. However, one can question the appropriateness of including married and unmarried mothers in the same classification as the social situation as a whole was undoubtedly different for an unmarried pregnant woman in the early 1900s than for one who was wed. When we analysed unmarried women as a separate social classification, the birth weights of their infants were significantly lower than for infants born to wed parents across all social classifications.

In conclusion, the combination of access to birth data from the early part of the past century and the possibility of follow up from birth through adulthood in Sweden, provides an excellent opportunity for the investigation of the influence of birth outcome on disease and mortality in later life. Such data from original records are rarely found in other countries long enough back in time to be able to study outcomes in late adulthood. The appropriate application of such data must however be considered, to ensure that the utilisation of these delivery records reflects the birthing practice of the time period in question.

Funding: this study was supported by The Swedish Medical Research Council (B96-27X-11659 and B96-19X-07509), the Faculty of Medicine Göteborg University, The Swedish Nutrition Foundation and the Wilhelm and Martina Lundgren Foundation.

Conflicts of interest: none.

1 Barker DJP, ed. Fetal and infant origins of adult disease. 1 st ed. London: BMJ, 1992

2 Barker DJP. Mothers, babies, and disease in later life. London: BMJ, 1994.

3 Barker DJP. The fetal origins of coronary heart disease. Acta Paediatr 1997;suppl 422:78-82.

4 Elford J, Whincup P, Shaper AG. Early life experience and cardiovascular disease: longitudinal and case-control studies. Int 7 Epidemiol 1991;20:833-44.

5 Rich-Edwards JW, Stampfer MJ, Manson JE, et al. Birth weight and risk of cardiovascular disease in a cohort of weight and risk of cardiovascular disease in a cohort of
women followed up since 1976. BMf 1997;315:396-400.

6 Leon DA, Lithell HO, Vågerö D, et al. Reduced fetal growth Leon DA, Lithell $\mathrm{HO}$, Vagerö $\mathrm{D}$, et al. Reduced fetal growth
rate and increased risk of death from ischaemic heart disease: cohort study of 15000 Swedish men and women disease: cohort study of 15000 Swedish

7 Barker DJP, Godfrey KM, Osmond C, et al. The relation of fetal length, ponderal index and head circumference to blood pressure and the risk of hypertension in adult life. Paediatr Perinat Epidemiol 1992;6:35-44.

8 Law CM, Shiell AW. Is blood pressure inversely related to birth weight? The strength of the evidence from a systematic review of the literature. F Hypertens 1996;14:935-41.

9 Koupilová I, Leon DA, McKeigue PM, et al. Is the effect of low birth weight on cardiovascular mortality mediated through high blood pressure? f Hypertens 1999;17:19-25.

10 Launer LJ, Hofman A, Grobbee DE. Relation between birth weight and blood pressure: longitudinal study of infants weight and blood pressure: longitudi
and children. $B M \mathcal{F} 1993 ; 307: 1451-4$.

11 Barker DJP, Hales CN, Fall CHD, et al. Type 2 (non-insulin-dependent) diabetes mellitus, hypertension and hyperlipidaemia (syndrome $\mathrm{X}$ ): relation to reduced etal growth. Diabetologia 1993;36:62-7.

12 Lithell HO, McKeigue PM, Berglund L, et al. Relation of size at birth to non-insulin dependent diabetes and insulin concentrations in men aged 50-60 years. BMf 1996;312: 406-10.

13 Rich-Edwards JW, Colditz GA, Stampfer MJ, et al. Birthweight and risk for type 2 diabetes mellitus in adult women. Ann Intern Med 1999;130:278-84.

14 Ekbom A, Trichopoulos D, Adami H-O, et al. Evidence of prenatal influences on breast cancer risk. Lancet 1992;340: 1015-18.

15 Michels KB, Trichopoulos D, Robins JM, et al. Birthweight as a risk factor for breast cancer. Lancet 1996;348:1542-6. 16 Sanderson M, Williams MA, Malone K, et al. Perinatal factors and risk of breast cancer. Epidemiology 1996;7:34-7. 
17 Tibblin G, Eriksson M, Cnattingius S, et al. High birthweight as a predictor of prostrate cancer risk. Epidemibirthweight as a pre
ology $1995 ; 6: 423-4$.

18 Paneth N. Early origins of coronary heart disease (the "Barker hypothesis"). BMF 1995;310:411-12.

19 Joseph KS, Kramer MS. Review of the evidence on fetal and early childhood antecedents of adult chronic disease. Epidemiol Rev 1996;18:158-74

20 Bengtsson C, Blohmé G, Hallberg L, et al. The study of women in Gothenburg 1968-1969 - a population study. General design, purpose and sampling results. Acta Med Scand 1973;193:311-18

21 Bengtsson C, Hallberg L, Hällström T, et al. The Population study of women in Göteborg 1974-75- the second phase of a longitudinal study. General design, purpose and sampling results. Scand F Soc Med 1978;6:49-54.

22 Bengtsson C, Gredmark T, Hallberg L, et al. The Population study of women in Gothenburg 1980-81 the third phase of a longitudinal study. Comparison between participants and a longitudinal study. Comparison between participant

23 Bengtsson C, Ahlqwist M, Andersson K, et al. The Prospective population study of women in Gothenburg, Sweden, 1968-69 to 1992-93. A 24-year follow-up study with special reference to participation, representativeness and mortality. Scand f Prim Health Care 1997;15:214-19.

24 Carlsson G. Social mobility and class structure. Lund, Sweden: GWK Gleerup, 1958.

25 Öberg L. Barnmorskan och läkaren-kompetens och konflikt $i$ svensk förlossningsvarrd 1870-1920 (The midwife and the doctor- competence and conflict in Swedish maternity care 1870-1920). Stockholm: Ordfronts förlag, 1996.

26 Altman DG. Practical statistics for medical research. 1st ed. London: Chapman and Hall, 1991.
27 MacGillivray I, Campbell DM, Thompson B, eds. Twinning and twins. London: John Wiley, 1988.

28 Höjeberg P. Jordemor. Barnmorskor och barnaföderskor $i$ Sverige (Midwives and childbirth in Sweden). Stockholm: Carlsson Bokförlag, 1991.

29 Eriksson M, Cnattingius S, Svärdsudd K, Tibblin G. Factors associated with birth weight in Sweden: the study of men born in 1913. F Epidemiol Community Health 1997; 51:19-23

30 Troy LM, Michels KB, Hunter DJ, et al. Self-reported birthweight and history of having been breastfed among younger women: An assessment of validity. Int 7 Epidemiol 1996;25:122-7.

31 Frankel S, Elwood P, Sweetnam P, et al. Birthweight, bodymass index in middle age, and incident coronary heart disease. Lancet 1996;348:1478-80.

32 Bland JM, Altman DG. Statistical methods for assessing agreement between two methods of clinical measurement. agreement between two

33 Siewert-Delle A, Ljungman S. The impact of birth weight and gestational age on blood pressure in adult life. A population-based study of 49-year-old men. Am 7 Hypertens 1998;11:946-53.

34 Barker DJP, Osmond C, Simmonds SJ, et al. The relation of small head circumference and thinness at birth to death from cardiovascular disease in adult life. BMF 1993;306: 422-6.

35 Ericson A, Eriksson M, Källén B, Zetterström R. Socioconomic variables and pregnancy outcome. Birthweight in singletons. Acta Paediatr Scand 1989;Suppl 360:48-55.

36 Seidman DS, Ever-Hadani P, Stevenson DK, et al. Birth order and birth weight reexamined. Obstet Gynecol $1988 ; 72: 158-62$. 